\title{
An integrated process involved coagulation and anaerobic sequencing batch reactor (ASBR) to remove organic substances in mechanical dewatering wastewater from municipal garbage
}

\author{
Rui Wang, Wentao Shang, Senlin Cai, Feiyun Sun* \\ Harbin Institute of Technology, Shenzhen, 518055, China
}

\begin{abstract}
Mechanical dewatering wastewater (MDW) from municipal garbage is a mixture that is quickly separated from raw domestic waste by high-pressure extrusion without a sump fermentation process. Alkali treatment-coagulation sedimentation-ASBR treatment technology was adopted in this study to treat SS and organic matter. The results showed that the optimum $\mathrm{pH}$ of the alkali treatment was 9.0, polyaluminum chloride (PAC) was the best coagulant for the coagulation and sedimentation of MDW. The optimal working condition were gotten with a $\mathrm{Ca}(\mathrm{OH})_{2}$ dosage of $200 \mathrm{mg} / \mathrm{L}$, a $\mathrm{pH}$ of 10.0 , and a PAC dosage of 800 $\mathrm{mg} / \mathrm{L}$, under the intermittent stirring mode of $250 \mathrm{r} / \mathrm{min}$ for $1 \mathrm{~min}$ and then $50 \mathrm{r} / \mathrm{min}$ for $10 \mathrm{~min}$. Perfect domestication effect of the ASBR was achieved under medium temperature for 28 days. The optimum conditions for ASBR were determined as follows: temperature was $35^{\circ} \mathrm{C}$, and organic loading rate $(\mathrm{OLR})$ was $6 \mathrm{~kg} \mathrm{COD} /(\mathrm{L} \cdot \mathrm{d})$. Analysis of the microbial community structure succession showed that the success rate of anaerobic microorganisms in medium temperature ASBR was fast and adaptable. This study provides technical support for the actual application.
\end{abstract}

\section{Introduction}

Continuous municipal solid wastes and garbage generation result to significant environmental impacts, and their disposal methods, such as landfilling, incineration and land treatment, inevitably resulted to harmful effects to human being[1]. In China, the municipal garbage that was typically classified into dry and wet components were mainly collected and transported in a mixed mode [2-3], which highly inhibited the energy and resources recovery efficiencies. The conventional dewatering technology for the mixed domestic garbage include mechanical compression and dewatering at the garbage transport station, the anaerobic fermentation dehydration in the garbage storage pond, etc. However, mechanical compression has its own shortages, such as negative environmental effects to vicinity circumstance and unstable dewatering efficiencies[4]. The anaerobic fermentation in the garbage incineration plant encountered the problems as well, e.g. the large footprint requirement[5]. In recent years, instant dewatering technology for municipal solid wastes by means of high-pressure or ultra-high-pressure was developed[6], which not only effectively reduce the solid wastes volumes, but also minimize the impact to the environments. Notwithstanding, the mechanical dewatering technique would generate one new kind wastewater, named as mechanical dewatering wastewater (MDW).

\footnotetext{
*Corresponding author: sun_fy@hit.edu.cn
} 
MDW is rather different from landfill leachate, its own characteristics, including high suspended solids (SS), organic content, high $\mathrm{NH}_{4}{ }^{+}-\mathrm{N}$ concentration, improper ratios of organic, nitrogen and phosphorus to biological process, and big variation in water quality and quantity. Hence, it is difficult to develop an effective treatment technology for MDW treatment. The organic substances in the MDW is the primary pollutant to be removed. Coagulation is a commonly applied technique to achieve efficient solid-liquid separation[7]. Anaerobic treatment is another promising treatment technology to treat high organic content wastewate[8-10]. Especially, anaerobic sequencing batch reactor (ASBR) can treat landfill leachate with high volumetric loading rates[11]. However, there was rare reports on the application of ASBR and pre-treatment methods to effectively treat MDW.

The present work employed ASBR and its pre-treatment method to treat MDW from municipal solid wastes. The effects of operation condition parameters on the treatment efficiencies on SS and organic substances from MDW were investigated, accordingly, the optimized parameters were obtained to instruct their practical application. Special attention was paid to the microbial community structure in the ASBR.

\section{Materials and Methods}

\subsection{MDW compositions}

The MDW was collected from the municipal solid wastes collection site located in Shenzhen Xiaping Municipal Waste Treatment Plant. In the ASBR experiments, synthesis wastewater was prepared according to the MDW composition, in which carbon source, ammonia, phosphorus compositions was sucrose, ammonium chloride, and potassium dihydrogen phosphate, respectively. The ratio of $\mathrm{C}: \mathrm{N}: \mathrm{P}$ in the synthesis wastewater was kept at 300:5:1. The trace elements were also added into the synthesis wastewater.

\subsection{Coagulation-ASBR system and operation condition parameters}

Fig.1 demonstrated the hybrid system, which was comprised of an alkali treatment tank, a coagulation tank, a sedimentation tank, a storage tank and an ASBR. The ASBR reactor had an inner diameter of $150 \mathrm{~mm}$, a height of $570 \mathrm{~mm}$, an effective volume of $9 \mathrm{~L}$, and its upper part was set as the gas collection chamber. The sludge inoculated to the ASBR was collected from the recirculation sludge in the Shenzhen Luofang Wastewater Treatment Plant and Guangming Farm Milk Steak, with mixed ratio of 9:1.

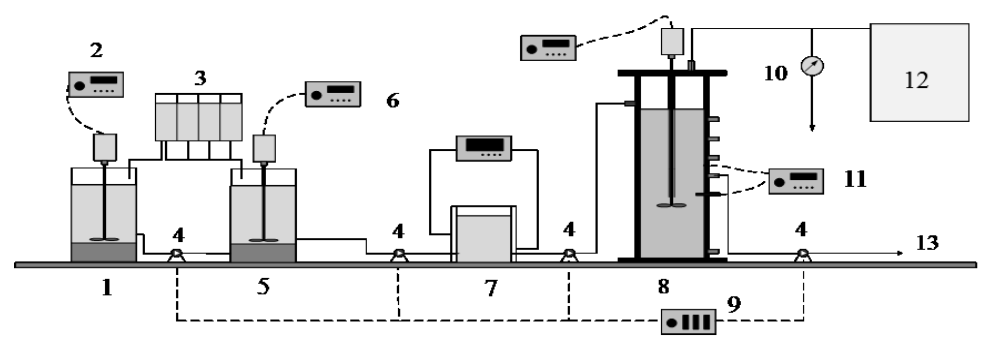

Fig. 1. Schematic diagram of the processing system in detail: (1)alkali treatment; (2)mixing controller; (3)dosing system; (4)pump; (5)coagulative precipitation tank; (6)cooling circulation system; (7)storage reservoir; (8)ASBR; (9)time controller; (10)wet flow gas meter; (11)temperature controller; (12)air pocket; (13)effluent.

\subsection{Analytical methods}

The treatment performances of coagulation and ASBR were indicated as $\mathrm{COD}, \mathrm{NH}_{4}{ }^{+}-$ $\mathrm{N}$ and TP removal efficiencies, and the adopted analytical methods of $\mathrm{NH}_{4}{ }^{+}-\mathrm{N}$ and TP are 
salicylic acid-hypochlorite spectrophotometry and ammonium molybdate spectrophotometry, respectively. Miseq high-throughput sequencing was used to analyze the microbial community structure shift in the ASBR anaerobic sludge[12].

\section{Results and discussion}

\subsection{MDW composition characteristics and its pre-treatment by $\mathrm{pH}$ adjustment}

Although the MDW content and concentration related closely with the solid wastes characteristics and climate, it was observed that, on average, the $\mathrm{pH}, \mathrm{SS}, \mathrm{COD}, \mathrm{BOD}_{5}$, $\mathrm{NH}_{4}{ }^{+}-\mathrm{N}, \mathrm{NO}_{3}{ }^{-}-\mathrm{N}, \mathrm{TN}$ and TP of the MDW was $4.56,4000 \mathrm{mg} / \mathrm{L}, 40100 \mathrm{mg} / \mathrm{L}, 16530 \mathrm{mg} / \mathrm{L}$, $873 \mathrm{mg} / \mathrm{L}, 180.5 \mathrm{mg} / \mathrm{L}, 1530 \mathrm{mg} / \mathrm{L}$ and $233 \mathrm{mg} / \mathrm{L}$, respectively. Considering that MDW contained a large portion of particular organic substances and heavy metals, a simple pretreatment by adjustment $\mathrm{pH}$ to above 8.0 could effectively remove a certain amount particular organic substances, and precipitate heavy metals into sediments. The study found that an increased $\mathrm{pH}$ resulted to an elevated COD and SS removal efficiencies. Once the $\mathrm{pH}$ increased to 9.0 , the removal rate of SS and COD reached $82 \%$ and $12 \%$, respectively. Continuous increasing of $\mathrm{pH}$ to above 9.0, the increasing trend of COD and SS removal rate became smooth, and hence, a $\mathrm{pH}$ of 9.0 was deemed as suitable for pre-treatment.

\subsection{Coagulation for MDW and its parameters optimization}

After the $\mathrm{pH}$ adjustment, the residue SS, and colloidal and soluble organic substances were removed by coagulation and sedimentation process. Varied coagulants, polyaluminum chloride (PAC), polyaluminum sulfate (PAS) and polyferric sulfate (PFS) were used to evaluate their effectiveness to break the stability of the colloidal organic, and to remove SS. The results showed that PAC had the best effect on the treatment of MDW. At the dosage of $800 \mathrm{mg} / \mathrm{L}$, PAC had the highest removal efficiencies in SS and COD in MDW, which reached to $57 \%$ and $7 \%$, respectively.

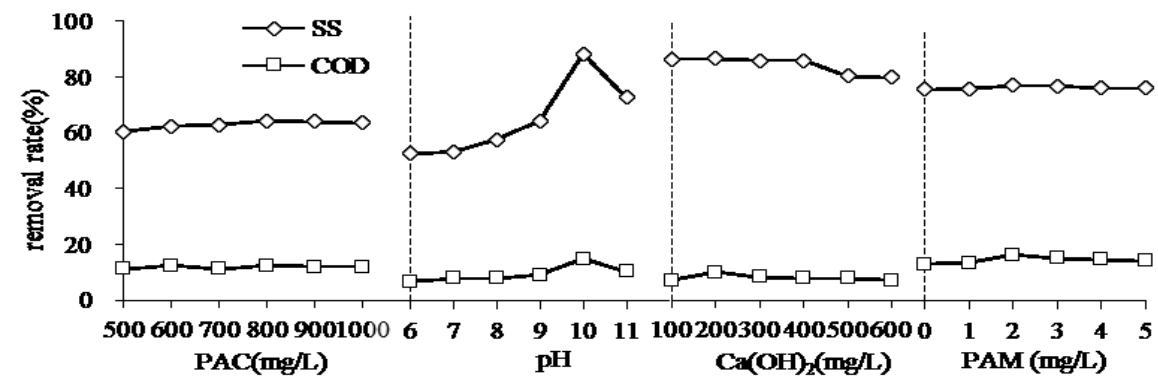

Fig. 2. Effect of PAC、pH、 $\mathrm{Ca}(\mathrm{OH})_{2}$ and $\mathrm{PAM}$ on $\mathrm{COD}$ and $\mathrm{SS}$ removal rate

Coagulation condition parameters, including PAC dosage, alkalinity, $\mathrm{Ca}(\mathrm{OH})_{2}$ dosage and PAM dosage were investigated to obtain the optimum SS and COD removal efficiencies. As shown in Fig. 2, with a PAC dosage of $800 \mathrm{mg} / \mathrm{L}$, a $\mathrm{Ca}(\mathrm{OH})_{2}$ dosage of 200 $\mathrm{mg} / \mathrm{L}, \mathrm{pH}$ of 10 , a rapid stirring velocity of $250 \mathrm{r} / \mathrm{min}$ for $1 \mathrm{~min}$, a PAM dosage of $2 \mathrm{mg} / \mathrm{L}$, and afterwards, a slow stirring velocity of $50 \mathrm{r} / \mathrm{min}$ for $10 \mathrm{~min}$, and a sedimentation time of above 40 min, more than $20 \%$ COD and $80 \%$ of SS could be effectively removed.

\subsection{ASBR for organic degradation from MDW}

\subsubsection{ASBR start-up and treatment performance}

A mixture sludge suspension with a SS concentration of around $27.8 \mathrm{~g} / \mathrm{L}$, comprised of concentrated sludge biomass was added as inoculated sludge to acclimate ASBR. For a 
quick start-up, synthetic wastewater was used firstly, and after more than 35 days acclimation, actual MDW was stepwise added into the ASBR feeding. Fig. 3 showed that in the initial stage of start-up, the sludge activity decreased firstly. Afterwards, MDW began to added gradually into the ASBR influent, after acclimation for 28 days, with an influent COD concentration of $12000 \mathrm{mg} / \mathrm{L}$, more than $97 \%$ COD could be stably removed. Meanwhile, the sludge biomass in the bulk showed good activities, the MLSS continuous increased and the SVI of sludge biomass decreased, reflected as a good settleability.

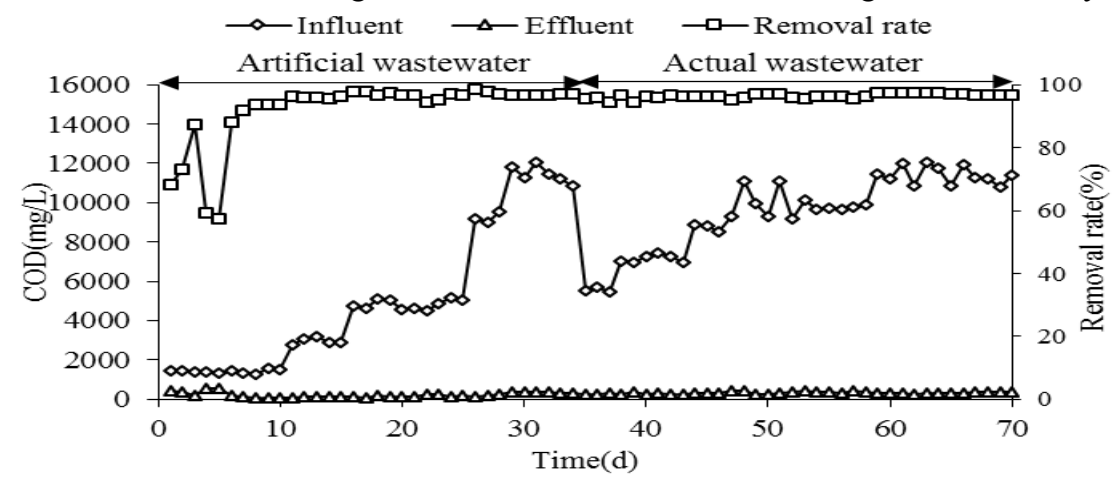

Fig. 3. COD changes in the initiation and acclimation of medium temperature ASBR

\subsubsection{Influential factors and condition parameters optimization}

\section{Effect of temperature on ASBR}

As one of the main condition affecting ASBR treatment performance, temperature mainly affected the degradation rate of organic pollutants by influencing the microorganism activity. Hence, two temperature, 25 and $35{ }^{\circ} \mathrm{C}$, was selected to evaluate temperature effect onto ASBR operation. Fig.4 (a) and (b) showed the changes of COD in the reactor during one typical reaction period at 25 and $35^{\circ} \mathrm{C}$. With an influent COD of $7500 \mathrm{mg} / \mathrm{L}$, the COD concentration in the two ASBRs showed an increasing trend in the first 30 min feeding phase, and then gradually decreased. Under the temperature of $35{ }^{\circ} \mathrm{C}$, the time taken to degrade COD to below $500 \mathrm{mg} / \mathrm{L}$ was $11 \mathrm{~h}$, which was rather quicker than that in $25{ }^{\circ} \mathrm{C}$ condition. Therefore, medium temperature was more beneficial to the ASBR performance.

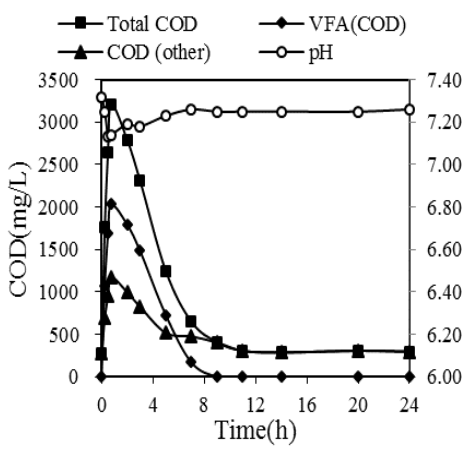

(a)

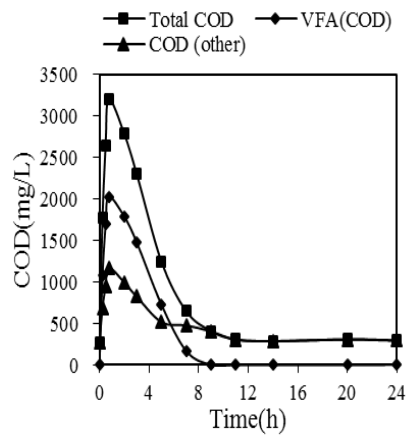

(b)

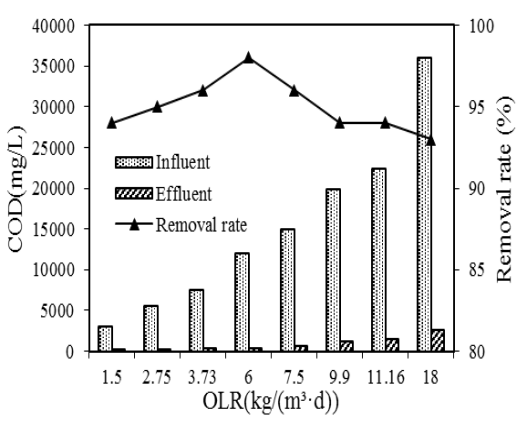

(c)

Fig. 4. (a) COD change during typical period of medium temperature ASBR; (b) COD change in typical period of normal temperature ASBR; (c)Effect of OLR on medium temperature ASBR.

\section{The impact of organic loading rate}

The organic loading rate is an important parameter to the anaerobic biological treatment process, which reflects both the influent COD concentration and the effect of 
HRT on anaerobic treatment, and also reflects the relationship between organic pollutants and anaerobic sludge. The effect of organic load range from 1.5 to $18 \mathrm{~kg} /\left(\mathrm{m}^{3} \cdot \mathrm{d}\right)$ on the treatment of ASBR was studied (Fig.4c). It can be seen that the removal rate of COD increased with the increase of OLR when OLR was low. The reason is that low OLR can not supply sufficient nutrients for microbial growth and reproduction.There is no material basis for granulation. After the sludge load is gradually increased, the anaerobic flora can obtain rich nutrients and energy, accelerate the formation of microorganisms, and produce extracellular polymers and gradually form a large amount of granular sludge, thereby the removal rate of COD is also improved. When the OLR was $6 \mathrm{~kg} /(\mathrm{L} \cdot \mathrm{d})$, the removal rate of COD was up to $98 \%$. While the COD removal rate decreased as the organic load increased. The main reason is that a large amount of granular sludge accumulates at the bottom of the reactor, which affects the uniformity of the water distribution of the reactor and reduces the rising flow rate. The amount of acid-producing bacteria and methanogenic bacteria attached to the mud surface is larger than the amount of large-grain sludge deposited on the bottom of the reactor, which affects the activity of the sludge[13-14].

\section{Microbial community structure changes during domestication}

Fig.5 showed the changes of bacterial classes during the acclimation of mediumtemperature ASBR. OP11, Bacteroides, TM7, Thick-walled, Proteobacteria, Mutant and Green Campylobacter were the dominant bacteria, which indicated that the diversity of microbial community was more rapid and adaptable. The following sample serial number MF3342、MF5500、MF8500、MF11760 and MF14480 represented temperature was medium , the matrix was waste water, and the COD were 3342、5500、8500、11760 and $14480 \mathrm{mg} / \mathrm{L}$, respectively.
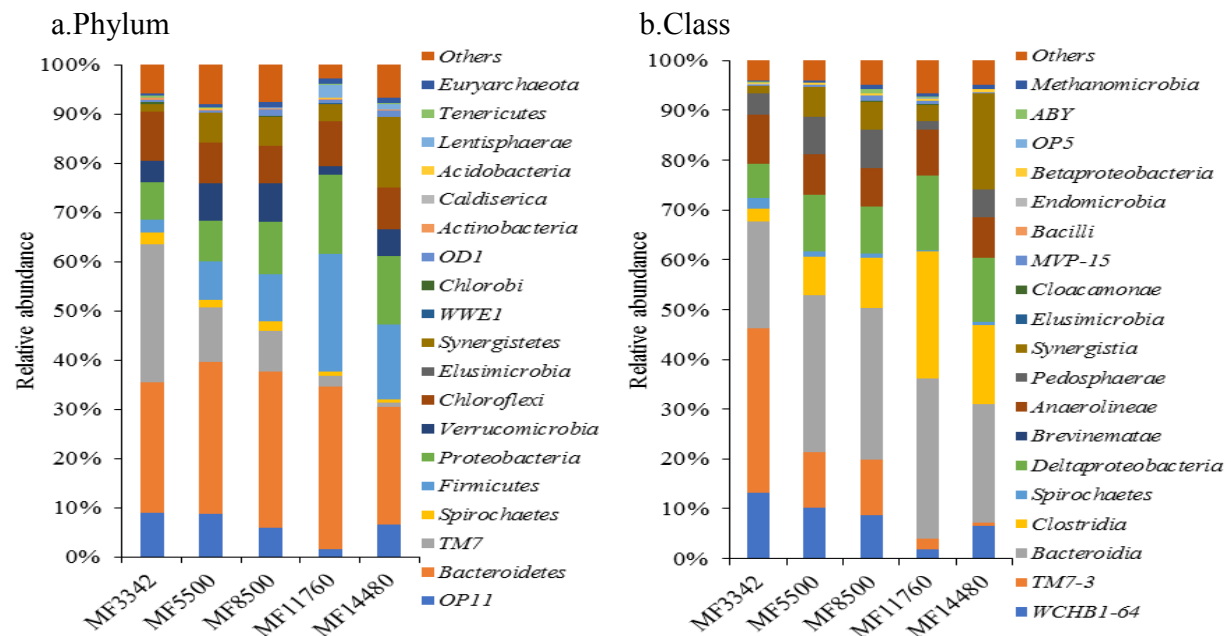

Fig. 5 the changes of bacterial gates and families in the process of domestic ASBR acclimation

\section{Conclusion}

The MDW from solid wastes varies greatly with rather complex compositions. The optimum $\mathrm{pH}$ for the alkali treatment was 9.0. Coagulation and sedimentation could further remove organic substance and SS, which depended significantly on the coagulant and condition parameters. The optimal treatment conditions were a $\mathrm{Ca}(\mathrm{OH})_{2}$ dosage of 200 $\mathrm{mg} / \mathrm{L}$, a $\mathrm{pH}$ of 10.0 , and a PAC dosage of $800 \mathrm{mg} / \mathrm{L}$, with an intermittent stirring conditions. Medium temperature ASBR could further remove organic substance from MDW, and its optimum operating conditions for ASBR were: medium temperature $35^{\circ} \mathrm{C}$, and an OLR of 
$6 \mathrm{~kg} \mathrm{COD} /(\mathrm{L} \cdot \mathrm{d})$. From the analysis of the microbial community structure, the diversity of microbial community in the ASBR was more rapid and adaptable, indicating that this hybrid system could effectively treat MWD organic substance and SS.

\section{Acknowledgement}

This research was supported by the Shenzhen Science and Technology Funding Project [grant number JCYJ20160406162038258, and JCYJ20170816102318538], Program of International S\&T Cooperation [grant number 2016YFE0123400]; the National Natural Science Foundation of China [grant numbers 51678183]; and the Project supported by Guangdong Natural Science Foundation [grant number 2017A030313285].

\section{References}

1. S. Thakare, S. Nandi, Study on Potential of Gasification Technology for Municipal Solid Waste (MSW) in Pune City, Energy Procedia, 90, 509-517(2016).

2. B.K. Adhikari, S. Barrington, J. Martinez, S. King, Characterization of food waste and bulking agents for composting, Waste Manag, 28, 795-804 (2008).

3. D.S. Shen, Y.Q. Yang, H.L. Huang, L.F. Hu, Y.Y. Long, Water state changes during the composting of kitchen waste, Waste Manag, 38, 381-387(2015).

4. M.Y. Zhou, J. Guan, Study on thermal compression filtration,drying dewatering principle and technique parameters, Coal Engineering, 5, 93-95(2010).

5. Y. Chen, H.Y. Ren, W.Q. Ruan, Project operation effect of anaerobic-aerobic process for leachate treatment of garbage incineration plant, Chinese Journal of Environmental Engineering, 9, 5750-5756(2015).

6. X. Xiao, T.Z. Guan, X.U. X.J. Xu, X. Zheng, X.H. Chen, G.F. Shi, L. M, Mechanical Sludge Dewatering by High-pressure Filtering Process in a Municipal Wastewater Treatment Plant, Urban Environment \& Urban Ecology, 26, 43-46(2013).

7. M. Sillanpää, M.C. Ncibi, A. Matilainen, M. Vepsäläinen, Removal of natural organic matter in drinking water treatment by coagulation: A comprehensive review, Chemosphere, 190, 54-71 (2018).

8. Y. Dai, J. Cheng, Research on the Union Process of Autothermal Thermophilic Aerobic and Anaerobic Digestion under Different Sludge Solid Contents, ENVIRON SCI TECHNOL, 39, 107-112 (2016).

9. A. Khalid, M. Arshad, M. Anjum, T. Mahmood, L. Dawson, The anaerobic digestion of solid organic waste, Waste Manag, 31, 1737-1744(2011).

10. X. Shi, K.Y. Leong, H.Y. Ng, Anaerobic treatment of pharmaceutical wastewater: A critical review, BIORESOURCE TECHNOL, 245, 1238-1244(2017).

11. G.D. Zupančič, A. Jemec, Anaerobic digestion of tannery waste: semi-continuous and anaerobic sequencing batch reactor processes, BIORESOURCE TECHNOL, 101, 2633(2010).

12. C.J. Chen, H.Q. Zhang, Y.Q. Wang, X.L. Yu, J.F. Wang, Y.L. Shen, Characteristics of Microbial Community in Each Compartment of ABR ANAMMOX Reactor Based on High-throughput Sequencing, Environmental Science, 37, 2652-2658 (2016).

13. E. Sánchez, R. Borja, L. Travieso, A. Martín, M.F. Colmenarejo, Effect of organic loading rate on the stability, operational parameters and performance of a secondary upflow anaerobic sludge bed reactor treating piggery waste, BIORESOURCE TECHNOL, 96, 335-344(2005).

14. F.X. Chebel, S.M. Ratusznei, J.A. Rodrigues, M. Zaiat, E. Foresti, Analysis of performance of an anaerobic sequencing batch reactor submitted to increasing organic load with different influent concentrations and cycle lengths., Applied Biochemistry \& Biotechnology, 133, 171-187 (2006). 